\title{
O QUE HÁ DE NOVO NO "NOVO" RACISMO DO BRASIL?
}

\author{
Marcus Eugênio Oliveira Lima ${ }^{1}$
}

\begin{abstract}
RESUMO
Nos últimos anos, o racismo se tornou mais aberto no Brasil; simultaneamente, vem ganhando força a percepção de que ele é, amiúde, um exagero das minorias ou uma retórica distorcida dos grupos que as defendem. Trata-se da narrativa ultraconservadora que concebe o racismo como "mimimi" dos negros. $\mathrm{Na}$ Europa e nos Estados Unidos, o racismo também voltou à agenda cotidiana, atuando como estruturante de opções políticas, a exemplo da eleição de Donald Trump e do Brexit. Neste artigo, procedemos a uma análise teórica do racismo no contexto de emergência dos discursos populistasconservadores da atual conjuntura brasileira. A perspectiva adotada é da psicologia social das relações intergrupais. A hipótese de análise é a de que, nos últimos anos, como consequência de um relativo avanço social, cultural e econômico das minorias, foi gerado um sentimento difuso, misto de nostalgia do passado e ressentimento, que alimenta formas mais abertas e virulentas de racismo.
\end{abstract}

Palavras-chave: Racismo. Atualidade. Conservadorismo. Brasil

\section{WHAT'S NEW IN BRAZIL'S "NEW" RACISM?}

\begin{abstract}
In recent years, racism has become more open in Brazil. At the same time, the perception that it is an exaggeration of minorities or a distorted rhetoric of those that defend them is growing. It is the ultraconservative narrative that conceives racism as "mimimi" of blacks. In Europe and the United States, racism has also returned to the day-to-day discussions, structuring political options, such as the election of Donald Trump and Brexit. In this article we present a theoretical analysis of racism in the context emergency of the populist-conservative discourses in Brazilian conjuncture. The perspective adopted is the social psychology of intergroup relations. The hypothesis is that, in recent years, as a consequence of a relative social, cultural and economic advancement of minorities, a diffuse feeling has been generated, mixed with nostalgia of the past and resentment, which feeds more open and virulent forms of racism.
\end{abstract}

Keywords: Racism. Nowdays. Conservadorism. Brazil

¿QUÉ HAY DE NUEVO EN EL "NUEVO" RACISMO DE BRASIL?

\section{RESUMEN}

Recientemente el racismo se ha vuelto más abierto en Brasil; al mismo tiempo, gana fuerza la percepción de que es una exageración de las minorías o una retórica distorsionada de grupos que las defienden. Se trata de la narrativa ultraconservadora que concibe el racismo como "mimimi" de los negros. En Europa y Estados Unidos racismo también volvió a la agenda cotidiana, actuando como estructurante de opciones políticas, a ejemplo de la elección de Donald Trump y del Brexit. Procedimos un análisis teórico del racismo en el contexto de emergencia de los discursos populistas-conservadores en Brasil. La perspectiva adoptada es la psicología social de las relaciones intergrupales. La hipótesis es que, en los últimos años, como consecuencia de un relativo avance social, cultural y económico de las minorías, se ha generado un sentimiento difuso, mixto de nostalgia del pasado y resentimiento, que alimenta formas más abiertas y virulentas de racismo.

Palabras clave: Racismo. Actualidad. Conservadorismo. Brasil

\footnotetext{
${ }^{1}$ Doutor em psicologia social pelo ISCTE - PT. Professor Associado do Departamento de Psicologia da Universidade Federal de Sergipe. e-mail marcuseolima@gmail.com
} 


\section{INTRODUÇÃO}

Há pouco tempo, o racismo no Brasil era algo da ordem do "ninguém sabe, ninguém viu"; algo como um preconceito de ter preconceito (FERNANDES, 1966). Falar sobre racismo soava estranho, tudo parecia em ordem, ainda que numa ordem hierárquica bem definida e não discutível, há muito consagrada em Casa-Grande \& Senzala: os brancos na sala, os índios nas matas e os negros na cozinha (FREYRE, 1933). Não obstante haver ecos de vozes dissonantes vindas, sobretudo, da sociologia e antropologia nacionais e de alguns brasilianistas, nada disso mobilizava o Estado ou abalava o cidadão comum a se importar com o racismo nacional.

Todavia, temos assistido no plano nacional, mas também em escala global, a um "retorno do reprimido". Vivemos nos últimos anos no Brasil um momento em que o termo "racismo" tem sido e será cada vez mais usado, assim como nos Estados Unidos da era Trump e na Europa dos nacionalismos de extrema-direita. O racismo se tornou pauta cotidiana de discussões no Brasil, mobilizando desde governos a cidadãos comuns, amplificado pela "caixa de ressonância" das redes sociais virtuais.

Nesse "novo" cenário, ganhou força a narrativa do racismo como "mimimi". É como se, na era da pós-verdade, todas as narrativas fossem meras construções sociais, retóricas elaboradas por grupos para alcançar ou legitimar posições de poder. O racismo, tal como o Golpe de 1964 e o efeito das vacinas no combate às infecções, seria mais uma dessas narrativas. Entretanto, como nos alerta Michiko Kakutani (2018), no livro "A morte da verdade: notas sobre a mentira na era Trump", não apenas existe uma verdade objetiva, como deixar de dizêla é uma questão importante, uma vez que iguala a indiferença à verdade.

Nos EUA, o racismo voltou a ser tema central (BOBO, 2017). Um estudo que monitorou as atitudes racistas de norte-americanos negros, asiáticos, brancos e latinos, verificou que, quando perguntados sobre os três maiores problemas da sociedade, a maioria dos negros citam o racismo em primeiro lugar (52\%); asiáticos e brancos citam o sistema de saúde (45\% e 39\%) e latinos, a imigração (39\%). O racismo foi o segundo mais citado para asiáticos e latinos e o terceiro, junto com terrorismo e segurança, pelos brancos. No mesmo estudo se observa que, para a maioria dos entrevistados, as relações raciais pioraram desde 2016: 75\% dos negros, 69\% dos asiáticos, 65\% dos latinos e $62 \%$ dos brancos (COHEN; FOWLER; MEDENICA; ROGOWSKI, 2017). O efeito da era Trump nas relações racializadas nos Estados Unidos pode ser um bom "balão de ensaio" para entender o que acontece e o que poderá vir acontecer no Brasil.

A Europa dos últimos anos foi varrida por uma onda de populismo reacionário, da Suécia à Suíça, da Bélgica à Bulgária, que exige a restauração da mítica idade de ouro dos 
estados-nação, homogêneos do ponto de vista cultural e racial (INGLEHART; NORRIS, 2016). Na Inglaterra, a turbulência econômica e política levou, em 23 de junho de 2016, a população a votar no referendum pela saída da Comunidade Europeia. Embora a vitória do Brexit tenha muitos significados, não se pode negar que um dos motivos centrais é a luta contra "outros internos", aqueles contra os quais a nação se definiu em termos identitários; oposição racista em relação, sobretudo, às minorias e os imigrantes (VIRDEE; MCGEEVER, 2018).

Neste artigo, analisamos teoricamente o racismo no Brasil, no contexto de emergência dos discursos populistas-conservadores, que marcaram os embates na campanha da eleição presidencial de 2018. A perspectiva adotada é a da psicologia social das relações intergrupais. Nossa hipótese de análise é a de que, nos últimos anos, como consequência das Políticas de Ação Afirmativa e de um relativo avanço social e econômico dos mais pobres em relação à classe média, foi gerado um sentimento difuso, misto de nostalgia do passado e ressentimento contra os negros e outras minorias, que alimentou formas mais abertas e virulentas de expressão do racismo. A argumentação se inicia com uma discussão sobre as principais formas de conceituação do racismo na psicologia social, para, em seguida, analisar as teorias do racismo e discutir as relações entre posição dos grupos, conjunturas políticas e formas de expressão do racismo. Ao final, propomos alguns tópicos para uma Agenda de análise do racismo na psicologia social brasileira.

\section{AS NOÇÕES E SUAS CONSEQUÊNCIAS}

Robert Miles (1989), numa perspectiva histórica, nos adverte que, quando a análise do racismo é errada, a estratégia política provavelmente não alcançará os objetivos propostos. Sem entrar no mérito da discussão sobre a adequação epistemológica do termo "errada" em ciências humanas, tal advertência é muito útil, pois sinaliza riscos importantes de confundirmos os objetos em análise, de minimizarmos os efeitos do conflito real ou simbólico entre os grupos e de, artificializando situações, descontextualizarmos os fenômenos das suas consequências e assim legitimarmos discursos de ódio racial.

A maior parte das análises psicossociais do racismo segue a definição de preconceito étnico proposta por Gordon Allport (1954), entendido como uma antipatia baseada em uma generalização defeituosa e inflexível, que pode ser sentido ou expresso, e que pode ser dirigido a um grupo como um todo ou a um indivíduo porque pertence a esse grupo. De acordo com essa noção, o problema central do preconceito racial são as ideias e sentimentos de evitação, rejeição, hostilidade e ódio. O próprio Allport propõe que as atitudes raciais se situam num continuum que varia do simples falar mal (antilocução) ao ódio e extermínio. 
Outra definição clássica de racismo afirma que é um conjunto de crenças de que as diferenças orgânicas, geneticamente transmitidas, estão intrinsecamente associadas à presença ou à ausência de certas habilidades ou características socialmente relevantes (van den Berghe, 1978). Ou ainda, uma configuração multidimensional de crenças, emoções e orientações comportamentais de discriminação relativamente a indivíduos membros de um grupo externo categorizado e objetivado a partir da cor da pele (VALA; LOPES; BRITO, 1999).

Há nessas noções de racismo pelo menos dois aspectos importantes a serem referidos. Primeiro, o racismo é entendido como uma forma de preconceito, preconceito racial (Brown, 1995) e, por isso, assimilado a uma noção mais individualizada de atitude, concebida como crenças e sentimentos que geram tendências ou disposições comportamentais. Segundo, e seguindo a mesma lógica, o racismo é considerado um tipo negativo de emoção: antipatia, raiva ou ódio em relação ao outro.

Essas noções de racismo estruturam a maioria das análises da psicologia social sobre o fenômeno. Elas não são equivocadas, como poderia nos levar a crer a asserção inicial de Miles (1989), mas se referem a uma dimensão específica e a formas particulares de manifestação de racismo, não sendo capazes de iluminar nossa compreensão sobre o racismo como fenômeno sistêmico.

Os sentimentos negativos vivenciados pelos racistas em relação à diferença, muitas vezes, não são sentimentos de hostilidade ou ódio, mas de desconforto, nervosismo, ansiedade e, algumas vezes, medo, como ocorre no racismo aversivo (GAERTNER; DOVIDIO, 1986). Muitas vezes, formas violentas de preconceito e de racismo convivem com ambivalência de sentimentos e mesmo "amor" pelo outro, como ocorre no preconceito paternalista (JACKMAN, 1994). Além disso, o racismo é um fenômeno estratégico das relações de dominação, sendo mais governado por motivações "frias" ou estratégicas que por "emoções quentes".

Em linhas gerais, podemos afimar que as análises do racismo na psicologia social consideram apenas o aspecto atitudinal do racismo, ou seja, a dimensão de preconceito do fenômeno; dando pouca ênfase à dimensão de supremacia ou dominação que o racismo engendra. Dizendo de outra forma, as análises raramente consideram os interesses, os contextos e os tipos de minorias envolvidos nas relações de poder entre grupos sociais.

O racismo é algo que põe o preconceito em ação, numa lógica do tipo "P + P”, ou seja, Preconceito + Poder (HOYT Jr., 2012), manifestando-se nas relações de dominação. Não obstante, o racismo possa ser concebido de forma mais individualizante como um tipo de preconceito - uma atitude, em uma concepção mais ampla e societal ele, é uma prática ou ação 
que visa à manutenção dos privilégios e desigualdades, os quais estruturam a sociedade em termos racializados.

Nesta linha de argumentação, podemos propor que, se os interesses nas relações são de controle ou dominação e se o status quo do grupo dominante está ameaçado, o racismo tornase mais saliente, aberto e infra-humanizador, quando a minoria alvo são os negros (LIMA; NEVES; SILVA, 2014) e, mesmo desumanizador, quando o alvo são os ciganos (LIMA, 2011). Por outro lado, se o status quo do grupo dominante não está ameaçado pela minoria e se são estáveis as outras condições, o racismo pode assumir uma expressão paternalista, substituindo as representações infra e desumanizadoras do outro, pelas infantilizantes, pitorescas ou caricatas, adotando uma estratégia de suposta proteção dos membros da minoria, quando estes são mulheres (JACKMAN, 1994), ou de discriminação velada e sutil, quando são negros (LIMA; VALA, 2004a), ou ainda de indiferença, se forem indígenas (LIMA; ALMEIDA, 2010).

Neste nosso "balão de ensaio" da produção do racismo, há ainda que se considerar o tipo de contexto normativo das relações racializadas. Quando a norma antirracista se torna saliente, as expressões caminham para os chamados "novos racismos" (CAMINO; SILVA; MACHADO, 2004; LIMA; VALA, 2004b); quando a norma se torna mais frouxa, as expressões podem assumir formas mais abertas ou flagrantes (GAERTNER; DOVIDIO, 1986), vinculando-se aos valores da competição e do individualismo (LIMA; PINHEIRO; PACHECO; LIMA, 2006; LINS; LIMA; SOUZA; NUNES; CAMINO, 2017). Entretanto, o espectro de ação da norma antirracista difere de minoria para minoria social (CRANDALL; ESHLEMAN; O'BRIEN, 2002), sendo mais forte para negros e mulheres, mais frouxo para homossexuais e quase inóquo para a proteção dos ciganos (LIMA; FARO; DOS SANTOS, 2016).

Neste sentido, o racismo, além de ser uma forma de representação negativada da diferença (VALA, 2015), é também um tipo de ideologia, cuja operação discursiva serve não só para inferiorizar e excluir, mas também para incluir e superiorizar (MILES, 1989). Em tal cenário, o desafio para a psicologia social é explicar como as ideologias racistas são interiorizadas pelas pessoas (WETHERELL, 1996), a fim de entender como se tornam significativas a ponto de motivarem ações extremistas como aquela, na qual, em 15 de março de 2019, na Nova Zelândia, um atirador invadiu duas mesquitas, na cidade de Christchurch, e matou 50 pessoas. $\mathrm{O}$ atirador neonazista, antes do atentando, publicou um manifesto intitulado "The Great Replacement", no qual expressa o ideário da extrema-direita europeia de que os brancos estariam sendo substituídos por imigrantes não brancos, de forma a ser preciso combater a imigração. 
O racismo não é um tipo qualquer de ideologia. Trata-se de uma ideologia da "falsa consciência”, uma versão parcial e deturpada dos fatos e da realidade para atender certos interesses. Um tipo de ideologia voltada para a legitimação, racionalização e justificação das assimetrias ou desigualdades entre os grupos (TYLER, 2006), ideologia com "adequabilidade prática" (MILES, 1989). Enfim, uma forma de ação social (WETHERELL; POTTER, 1992). Ele parte do preconceito para engendrar a legitimação da discriminação (JACKMAN; MUHA, 1984; PEREIRA; VALA, 2010).

O racismo se apresenta com lógicas próprias e formas de expressão intercambiáveis, de forma que é preciso estudar, para além das atitudes raciais individuais, os mecanismos, práticas e relações que produzem e reproduzem a desigualdade racial em todos os níveis (BONILLASILVA, 2015).

\section{AS LÓGICAS E FORMAS DE EXPRESSÃO}

Parte da psicologia social de inspiração europeia procura analisar os objetos sociais considerando diferentes níveis ou planos. A tentativa é articular as explicações de ordem individual com as explicações de ordem societal (CAMINO, 1996); de mostrar "como os indivíduos dispõem de processos que lhes permitem funcionar em sociedade e, de maneira complementar, como as dinâmicas sociais, particularmente interacionais, posicionais ou de valores e de crenças gerais, orientam o funcionamento desses processos" (DOISE, 2002, p. 27). Nessa perspectiva, análises que articulam vários níveis são heuristicamente mais completas.

Wieviorka (1995) propõe uma classificação do racismo em diferentes níveis, transitando do individual ao cultural e institucional. Num primeiro nível, teríamos o infrarracismo, situado no plano das emoções e sentimentos individuais, muitas vezes não conscientes e sem organização de ações. No segundo nível, atua o racismo fragmentado, que se expressaria de forma mais precisa e aberta, podendo ser percebido e pesquisado. No terceiro nível, temos o racismo político, que inspira pressões e debates sociais, mobilizando a agenda social. Nesse estágio, o racismo começa a integrar teorias e ser assunto de discussões, reivindicando ou criando um espaço ideológico. O quarto nível, do racismo total, ocorre quando o Estado ou a sociedade é organizado em termos racistas, produzindo programas de exclusão em massa que envolvem, de forma sistêmica, todas as instituições sociais na reprodução do racismo.

Integrando os níveis de análise de Doise (2002) com as lógicas de expressão do racismo propostas por Wieviorka (1995), é possível entender a estreita relação entre o contexto social de emergência, o tipo de relação e a forma de manifestação do racismo. A figura 1 apresenta um esboço dessa tentativa de compreensão. Quando as relações estão mais pendentes para o polo interpessoal, o racismo é mais difuso e menos organizado, assemelhando-se às noções de 
preconceito. Quando a relação transita para o polo intergrupal, o racismo começa a se organizar como força política, definindo padrões culturais e podendo até estruturar as instituições do Estado. Não obstante o caráter estático e aparentemente dicotômico da imagem proposta, não se pode perder de vista o constante trânsito de posições e retroalimentações das instâncias individuais e culturais. O racismo é sempre, e ao mesmo tempo, individual e cultural. Falta à nossa imagem a dimensão dos interesses sociais e do tipo de minoria social envolvida na relação. Fatores que também interferem na produção do racismo.

Figura 1 - Esquematização das relações entre as lógicas e níveis de expressão do racismo

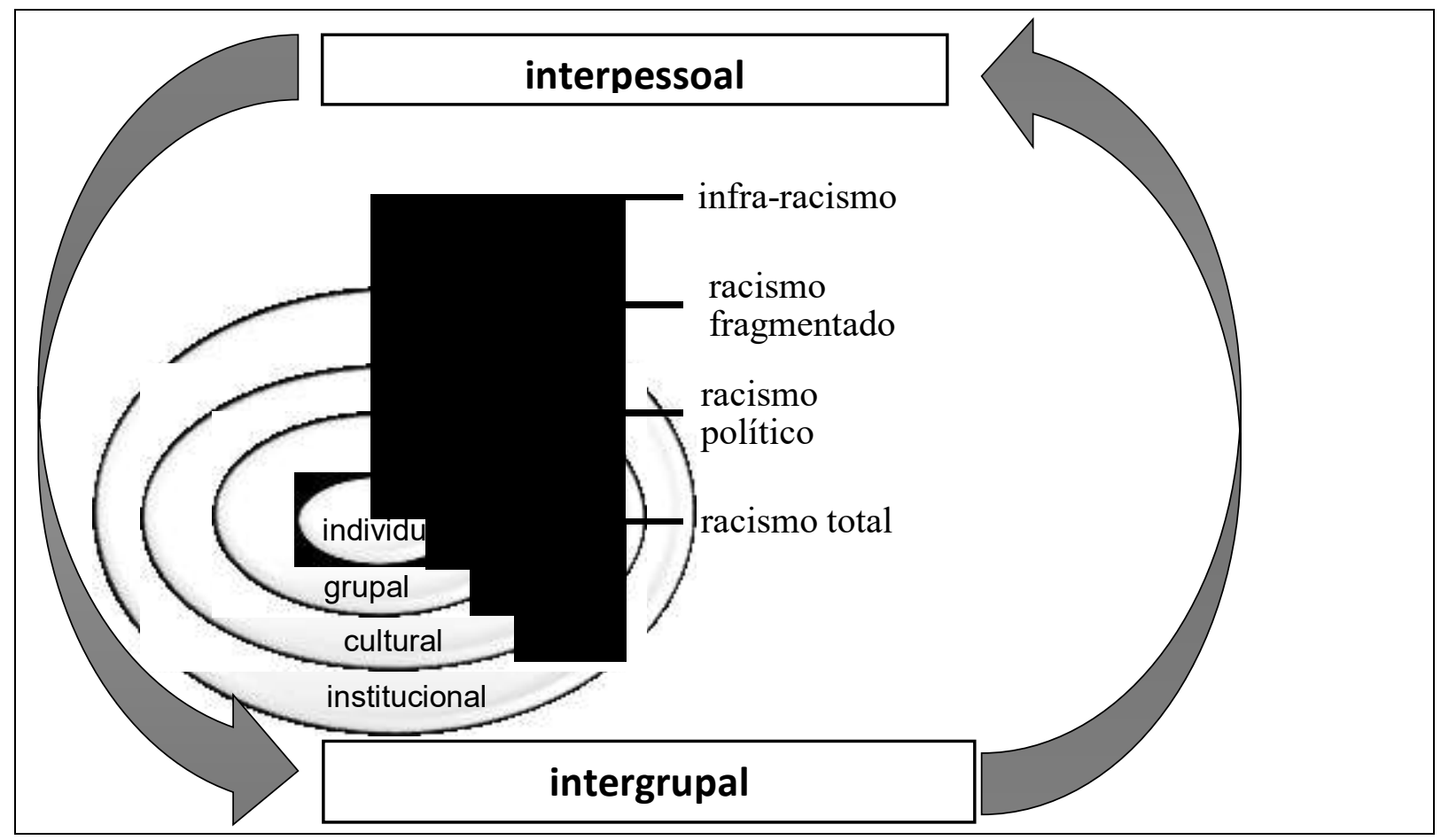

Fonte: Elaborado pelo autor.

Aspectos individuais, de pesonalidade dos envolvidos nas relações, também devem ser considerados na produção do racismo. Há ampla evidência na psicologia social sobre os efeitos dessa dimensão nas diferenças de expressão do fenômeno (e.g., ABOUD, 1988; FISHBEIN, 2002; HIRSCHFELD, 1998). Existem, inclusive, teorias clássicas que afirmam a força desses fatores, a exemplo da teoria da Personalidade Autoritária (ADORNO; FRENKELBRUNSWICK; LEVINSON; SANFORD, 1950) e da dominância social (SIDANIUS; PRATTO; BOBO, 1996).

Entretanto, como demonstra Petrigrew (1958), são os contextos normativos das relações entre grupos, sejam eles políticos, culturais, sociais e econômicos, que dão o tom, a força e a abrangência das expressões do racismo e da "escolha" das suas vítimas. Alguns analistas chegam mesmo a afirmar que o surgimento do racismo moderno está ligado à decomposição 
das sociedades industriais e à consequente elevação dos níveis de desemprego e encolhimento dos Estados de Bem-Estar (WIEVIORKA, 1995); de tal modo que, contextos de competição social não somente intensificam a frequência das expressões do racismo, como também tornam as suas formas mais abertas e violentas.

Nesse sentido, o racismo pode ser entendido como consequência de uma confluência de fatores, com destaque para: 1) os de personalidade ou individuais; 2) os do contexto das relações; 3) os tipos de grupos envolvidos; 4) os interesses que estruturam a relação entre os grupos; 5) a posição dos grupos na estrutura de poder e o quanto a minoria é percebida como ameaçadora dessa posição e 6) a identidade social dos membros individuais envolvidos na relação.

A título de ilustração, vamos pensar em casos paradigmáticos de racismo extremo, como o de Brenton Harrison Tarrant, 28 anos, o atirador que matou 50 pessoas nas mesquitas da Nova Zelândia. Ele era uma pessoa comum, que gostava de viajar, mas que mantinha poucas relações sociais e era fixado em armas e games de ação. Do ponto de vista social, o atirador se identificava com grupos específicos, de supremacistas brancos, e percebia suas vítimas como representantes de grupos que ameaçavam a posição do seu grupo ou às suas identidades social e pessoal.

No caso relatado, o contexto de relações intergrupais aponta para uma ascensão dos discursos de intolerância e ódio à diferença, inclusive com crescimento expressivo da representação política de extrema-direita. A minoria escolhida foram os muçulmanos que, no contexto de relações da Austrália (país do atirador) e da Nova Zelândia (onde aconteceu o morticínio), constituem o segundo maior grupo religioso. Podemos supor que os interesses grupais envolvidos foram o da separação, inferiorização e extermínio da diferença.

Todavia, se pensarmos em outro crime, agora o episódio ocorrido no dia 13 de março de 2019, em Suzano - SP, no qual dois jovens, usando um tipo de máscara que é símbolo de grupos neonazistas do século XXI, invadiram um colégio para matar sete pessoas, sendo cinco delas de cor negra (FOLHA, 13/03/19); podemos supor que o racismo que motivou a ação era um racismo difuso, fragmentado, que provavelmente se aliou a várias frustrações e bloqueios emocionais individuais do atirador para gerar a ação terrorista. No caso do atirador australiano, temos um racismo dirigido de forma mais específica, planejado como ação, um racismo do tipo político-estratégico, preocupado com a espetacularização da ação para ganhar mais adeptos. Algo semelhante ao que motivou Anders Behring Breivik, atirador também de extrema-direita, a matar 77 pessoas na Noruega, no dia 22 de julho de 2011. Neste sentido, o racismo parte de motivações psicológicas e políticas para construir, salientar e hierarquizar as diferenças. 


\section{CRISE, AMEAÇA IDENTITÁRIA E RACISMO}

Depois deste percurso terminológico, podemos voltar à questão que motiva este texto: “o que há de novo no novo racismo do Brasil?” Talvez uma primeira tentativa de resposta seja o surgimento de movimentos de extrema-direita, com ampla repercussão política no país. De fato, o racismo brasileiro, até o fim do século XX, tinha vergonha de se mostrar, podendo ser entendido como um "preconceito de ter preconceito":

O que há de mais evidente nas atitudes dos brasileiros diante do preconceito de cor é a tendência a considerá-lo como algo ultrajante (para quem sofre) e degradante (para quem o pratica). Portanto, o que fica no centro das preocupações, das apreensões e, mesmo, das obsessões é o preconceito de ter preconceito. (FERNANDES, 1966, p. 33)

Provavelmente até início dos anos 2000, o racismo nacional se manteve preocupado em esconder sua face mais violenta e agressiva, mostrando-se "cordial" ou "sutil" nas suas manifestações (TURRA; VENTURI, 1995). O reconhecimento oficial por parte do Governo Federal da existência de racismo no Brasil, na década de 1990, e a consequente criação dos Programas de Políticas de Ação Afirmativa, sobretudo nas universidades, produziram, juntamente com outros fatores, as condições necessárias para o surgimento de discursos e práticas sociais mais flagrantemente racistas, considerando que um dos vetores que alimenta o racismo é o senso de posição grupal. Há evidências dessa transformação de um racismo paternalista, zeloso de uma dominação docilizada, para um racismo do tipo infra-humanizador, depois da implantação das cotas nas universidades do Brasil (LIMA; NEVES; SILVA, 2014).

Podemos então argumentar que o avanço social e econômico da minoria racial do Brasil criou as condições para a emergência de discursos ressentidos pela suposta perda de poder por parte de brancos e pardos da classe média. Estes fatores, aliados à crise econômica internacional de 2008 e à crise do Brasil desde 2013, fomentaram o surgimento e fortalecimento das alternativas políticas de extrema-direita.

Trata-se, antes de tudo, de um fenômeno mundial, que repercutiu no Brasil com força especial. Até recentemente, a extrema-direita nos Estados Unidos ocupava uma franja cultural e política periférica, um tipo de subcultura obscura de guetos inexpressivos. Isso perdurou até a eleição de Donald Trump, em 2016, quando ela começou a dominar o cenário cultural e político norte-americano (MICHAEL, 2017). Para esse autor, o avanço da extrema-direita norte-americana mistura elementos de "nacionalismo branco" com liberalismo econômico, conservadorismo cultural e moral, isolacionismo e populismo.

Outros dois fenômenos são importantes na emergência dos populismos de extremadireita nos EUA: o conspiracionismo e o poder de propagação de notícias falsas via internet. 
As teorias da conspiração geralmente propõem, em enredos escatológicos, que sociedades secretas e globalistas estão minando o tecido das nações. A Internet, sobretudo as redes sociais, facilitaram a disseminação desse tipo de teoria e passaram a ocupar o espaço ideológico da grande mídia nos Estados Unidos (MICHAEL, 2017).

A necessidade dos norte-americanos por alternativas populistas pode ser explicada por duas teorias complementares. Por um lado, a teoria da "demanda econômica" enfatiza as consequências das mudanças profundas na força de trabalho com os processos pós-industriais. Tudo isso produziu um colapso da indústria manufatureira, implicando fluxos globais de trabalho, bens, pessoas e capital. De forma específica, aumentou o afluxo de migrantes e refugiados e impactou no encolhimento das redes de proteção social, com as políticas de austeridade neoliberais, criando um caldo de crescente insegurança econômica e privação social, que alimentou o ressentimento popular contra as classes políticas. Por outro lado, a tese da "demanda cultural" postula que o avanço do populismo pode ser explicado também como uma reação contra a ameaça de perda da identidade cultural, afetando a "segurança existencial" dos mais conservadores. Pautas como igualdade de gênero, defesa das orientações sexuais não hegemônicas, questões ambientais, estariam no centro dessa percepção de ameaça, sendo exploradas pelos movimentos populistas (INGLEHART; NORRIS, 2016).

$\mathrm{Na}$ Europa, o movimento de expansão da extrema-direita tem razões históricas que formam matrizes para o mundo inteiro. A ascensão dos populismos reacionários pode ser explicada por uma abordagem da demanda e outra da oferta. A primeira focada em queixas e a outra em restrições de oportunidades políticas. As consequências políticas seriam variadas: protestos contra as políticas de imigração; luta por integração e ordem; percepção de ameaça à cultura dominante e o sentimento de privação econômica. Os seguidores dessas propostas não são uniformes; há desde pessoas de baixa escolaridade até jovens com nível educacional elevado (ver MUIS; IMMERZEEL, 2017).

Essas características parecem descrever também o que aconteceu no Brasil, desde os difusos movimentos de protesto político nas ruas, em 2013, passando pelo impeachment até a eleição de um candidato de extrema-direita para a presidência da república, em 2018. Discursos de extrema-direita ganharam eco na sociedade brasileira usando uma retórica que era um misto de conservadorismo moral com liberalismo político, assim como nos EUA de Trump. Como consequência, as minorias sociais se tornaram alvo de expressões mais abertas de preconceito e de racismo, com significativo crescimento, a partir de 2017, dos crimes a ele associados, seja a injúria (ARCOVERDE, 27/07/18), sejam casos de ódio em estádios de futebol (ESTADÃO, 23/10/17), seja ainda a discriminação de forma mais geral (DESTAK, 20/11/18). 


\section{AS POLÍTICAS DA DIFERENÇA E O RACISMO}

A diferença, percebida ou construída, é núcleo duro do racismo, uma vez que ele pode ser entendido como uma recusa, uma incapacidade ou uma impossibilidade de aceitar o diferente, enfim, uma heterofobia (ROKEACH, 1960). Ou, por outro lado, porque precisa da diferença para legitimar as assimetrias ou desiguldades de acesso entre os grupos, não aceitando, neste caso, as semelhanças ameaçadoras às identidades e posições de poder: uma heterofília (TAJFEL, 1981). Num caso, trata-se de um racismo assimilacionista; no outro, um racismo diferencialista. Em ambos, o que define o trato da diferença, se positivo ou negativo, são os tipos de grupos e os interesses envolvidos nas relações (VALA; LIMA, 2002), como ilustrado por Allport (1954, p. 189):

Por que tantas pessoas admiram Abraham Lincoln? Elas podem justificar dizendo que é porque ele era avaro, trabalhador, curioso, ambicioso, dedicado aos direitos das pessoas comuns e bem-sucedido. Por que tantas pessoas não gostam dos judeus? Elas podem justificar dizendo que é porque são avaros, trabalhadores, curiosos, ambiciosos, dedicados aos direitos das pessoas comuns e bem-sucedidos.

Não é por acaso que os principais modelos de combate ao preconceito e ao racismo focam a ideia de educação multicultural, na tentativa de ensinarem pessoas e grupos a lidar com a diferença. Na psicologia, um dos modelos mais influentes para o entendimento dessa questão propõem dois eixos: "Busca vs. Desinteresse em manter a identidade ou bagagem cultural do grupo" e "Busca vs. Evitação das relações com os outros (diferentes)". No meio desse continuum de forças, surgem quatro possíveis consequências do contato com a diferença: 1) integração, quando a diferença é aceita e respeitada; 2) assimilação, quando a diferença da minoria é engolida no contato com a maioria social; 3) separação, quando a minoria se isola da minoria para proteger sua diferença e 4) marginalização, quando a maioria segrega a minoria (BERRY; POORTINGA; SEGALL; DASEN, 1992).

Em linhas gerais, as posições sobre a questão da diferença e da igualdade estruturam as posições políticas de esquerda e de direita. Essas posições podem nos ajudar a entender o que há de novo no novo racismo, uma vez que, no cerne do racismo, está sempre a questão da diferença.

Antônio Pierucci, em "ciladas da diferença", ajuda-nos a entender porque os movimentos de extrema-direita têm, nos últimos tempos, levado vantagem na Europa, nos EUA e mais recentemente no Brasil. Para Pierucci (1990), a direita trata a questão da diferença de uma forma muito simples e direta: "Os seres humanos não são iguais porque não nascem iguais e, portanto, não podem ser tratados como iguais."; ao passo que a narrativa da esquerda sobre a diferença é mais complexa e, portanto, mais difícil de ser assimilada “Os seres humanos não 
são iguais porque não nascem iguais e, portanto, precisam ser tratados como iguais." Desta forma, continua Pierucci, para a direita a escolha entre igualdade e diferença é muito mais simples que para a esquerda. Esta deve abraçar a diferença, sem abrir mão da igualdade; aquela abraça a diferença para legitimar a desigualdade. É assim que adentramos no campo das "Ciladas da diferença". Nele, tanto os que se colocam à esquerda do espectro político quanto os que se colocam à direita, afirmam as diferenças; ainda que com razões e intenções diversas.

O movimento típico tanto da direita quanto da esquerda política, de rejeição ou de valorização da diferença, é sempre posterior à afirmação da mesma e, como nos lembra o próprio Pierucci (1990) e toda a psicologia social, toda diferenciação é uma hierarquização. Essa situação causaria ou um embaçamento do foco de ação ou um obscurecimento das diferenças ideológicas entre a direita e a esquerda (PIERUCCI, 1990), levando muitas vezes o cidadão comum a abdicar de raciocínios mais abstratos do tipo "igualdade como equidade ou como projeto político" e adotar lógicas mais simples e comezinhas, do tipo "somos iguais aos iguais a nós", máxima traduzida na perfeição por um "meme" dos discursos conservadores no Brasil de hoje: "Direitos humanos para seres humanos direitos". A este respeito, vale a pena reproduzir uma das falas de um dos entrevistados de Pierucci (1990, p. 17):

"Iguais?! Que que há, está me estranhando? Fazer o quê? A vida é assim, azar! Tratar como nosso irmão?! Eu trabalhei quarenta anos, não posso ser irmã de vagabundo. O que é isso, está me confundindo por que agora? Porque negro é isso...Todo mundo sabe que há racismo, sempre houve e vai haver até o fim da morte, amém. Negro é negro, branco é branco, azul é azul, vermelho é vermelho. E preto é preto. Não vem que não tem. Essas demagogias é bom é em época de eleição. Isso é demagogia, isso é falsidade, isso é falta de religião católica apostólica romana. (Dona Mariauta, 58 anos, São Paulo, 1980).

Evidentemente, que o efeito de adessão às propostas conservadoras no Brasil de hoje não decorre apenas da maior simplicidade cognitiva das mesmas. Trata-se de algo muito mais complexo, que remonta aos vetores do racismo que tentamos representar na figura 1. Há, além de fatores individuais e dos elementos de defesa do status quo dos grupos, fatores culturais e históricos amplos. O conservadorismo e autoritarismo de períodos históricos passados permanecem presentes no Estado brasileiro, constituindo-se um caldo de cultura latente que se manifesta como prática de paternalismo e assistencialismo repressivos, de valorização da força para resolução dos problemas sociais, de preocupação com a ordem social e de intolerância com as diferenças (CRUZ, 2010). Tudo isso, segundo a mesma autora, seria intensificado pelo processo de globalização das economias que torna as divisões sociais mais evidentes e amplifica a luta de interesses por manutenção das posições grupais no sistema de poder.

Ao acrescentarmos, nesta análise, a ascensão social e econômica, ainda que tímida, de algumas minorias sociais e a percepção de ameaça que ela produz nos grupos mais bem 
instalados na estrutura de poder, temos uma explicação possível para a maior virulência dos discursos e ações racistas e uma maior adesão a eles no Brasil dos últimos anos. O crescimento do racismo se associa ao recrudescimento do autoritarismo.

Uma pesquisa promovida pelo Fórum Brasileiro de Segurança Pública, em 2017, e conduzida pelo Instituto Datafolha, com amostra representativa nacional, demonstrou que, numa escala de 10 pontos, os entrevistados obtêm média de 8,1 no endosso a 17 afirmações autoritárias. Tal endosso aumenta conforme cresce a idade e decrescem escolarização e renda dos entrevistados (FOLHA, 06/10/17).

Nesse sentido, a mesma leitura que a Escola de Frankfurt fazia sobre o surgimento do autoritarismo alemão, a partir do racismo, expressa no segmento de texto abaixo, pode ser feita sobre recrudescimento ou reemergência do racismo mais flagrante:

O tema central do trabalho é um conceito relativamente novo - o advento de uma espécie "antropológica" que chamamos de tipo autoritário de homem. Ao contrário do preconceituoso do estilo anterior, ele parece combinar ideias e habilidades que são típicas de uma sociedade altamente industrializada com crenças irracionais ou antirracionais. Ele é ao mesmo tempo esclarecido e supersticioso, orgulhoso de ser individualista e em constante temor de não ser como todos os outros, zeloso de sua independência e inclinado a se submeter cegamente ao poder e à autoridade (HORKHEIMER, 1950, p. IX citado em LIMA; SANTOS, 2018, p. 124).

A reemergência do racismo flagrante de séculos passados no Brasil de hoje, leva-nos a refletir sobre duas das principais características desse fenômeno: a flexibilidade e persistência.

\section{FLEXIBILIDADE E PERSISTÊNCIA DO RACISMO}

A palavra "vírus" deriva do latim (vîrus) que significa fluido venenoso ou toxina. A Biologia nos ensina que os vírus parasitam células e tecidos, modificando seu metabolismo, provocando degeneração e morte e, finalmente, que se reproduzem e evoluem em resposta ao ambiente interno e externo dos organismos infectados. Essas características permitem afirmar que, em termos psicossociais, o racismo atua como um vírus. Ele sofre mutações e evolui para formas diferentes, que são mais difíceis de reconhecer e de combater (DOVIDIO; GAERTNER, 1998); ele tem a capacidade de gerar novas colônias para uma doença que não temos certeza da cura (FREDRICKSON, 2002), podendo ser concebido como um "conjunto de crenças dinamicamente estruturadas que são capazes de sofrer transformações adaptativas" (VALA; PEREIRA, 2012, p. 67).

A imagem do racismo como um vírus é poderosa, pois nos permite expressar a flexibilidade e persistência do fenômeno. Durante algum tempo, se acreditou que o racismo estava diminuindo, já que os estereótipos dos negros nos Estados Unidos tornaram-se menos 
negativos (BROWN, 1995); o mesmo acontecia no Brasil (LIMA, 2002); enquanto, na Europa, aumentava a solidariedade em relação aos imigrantes (BEN BRIKA; LEMAINE; JACKSON, 1997). Tratava-se de mudanças na expressão do racismo, das formas mais abertas e flagrantes para outras mais sutis e disfarçadas (LIMA; VALA, 2004b), em decorrência das pressões de novos contextos normativos, emergidos, sobretudo, depois da Segunda Guerra Mundial.

Todavia, o vírus do racismo transmutou suas expressões para conviver com as normas e delas se alimentar. Nos Estados Unidos e no Canadá, surgiu o "smiling racism" (CODJOE 2002), um tipo de expressão do racismo adaptada à norma antirracista, caracterizada por quatro traços: 1) tratamento diferente dispensado ao membro da minoria racializada, 2) múltiplas interpretações da situação, 3) razões socialmente aceitáveis para as ações e 4) ausência de sanção legal para o autor (JAVORČÍKOVÁ, 2005). Para ilustrar as quatro características citadas, basta pensar em uma abordagem policial a um grupo de jovens negros no Brasil ou mesmo o "zelo", muitas vezes excessivo, dispensado pelo pessoal das alfândegas aos membros de certas minorias culturais nos aeroportos internacionais.

Ilustrativos do mesmo "racismo sorridente" é a criação, por parte das imobiliárias, de maiores dificuldades para negros comprarem ou alugarem casas em bairros ricos nos Estados Unidos, produzindo uma nova discriminação residencial, bem como a elaboração de uma agenda política racial que evita referências raciais diretas, configurando assim, o chamado "color-blind racism" ou ainda o "racismo sem racistas" (BONILLA-SILVA, 2013).

No caso do Brasil, podemos citar o "racismo cordial" (TURRA; VENTURI, 1995) e, mais recentemente, como invenção dos conservadores mais reacionários, nas eleições presidenciais de 2018, o racismo vitimista, o chamado "mimimi" das minorias, de acordo com o qual os negros e outras minorias estariam dramaticamente atribuindo ao racismo ou a outros preconceitos os infortúnios que dizem sofrer (LIMA; ARAUJO; BARBOSA; ALMEIDA, sob revisão).

Em todos os casos citados, os mecanismos de reprodução dos privilégios raciais tornamse sutis. Trata-se de um racismo do tipo "deixe tudo como está" ou racismo "laissez faire" (BOBO; KLUEGEL, 1997). Enquanto os velhos ou tradicionais racismos operam pela hierarquização das diferenças biologizadas ou racializadas, absolutizando a diferença para consumar sua rejeição separadora ou marginalizadora (GUILLAUMIN, 1992), os novos racismos operam pela essencialização/hierarquização das diferenças culturais, relativizando-as para universalizar as hierarquias e, assim, consumar a inferiorização, integradora ou assimiladora, da diferença (TAGUIEFF, 1995; VALA; BRITO; LOPES, 1999). 
Para superarmos a aparente dicotomia entre "novos" e "velhos" racismos, devemos considerar que o racismo atua sempre em muitos e interconectados níveis. No nível institucional, ele atua como sistema ideológico, cuja prática é a materialização e legitimação das desigualdades entre os grupos. No nível das interações sociais e da formação das crenças individuais, ele exerce função de norma social, podendo ser rejeitado, aceito, gerar identificação ou internalização (KELMAN, 1958). Todo esse espectro de ação pode ser percebido ou não pelos indivíduos, os quais podem tornar-se pré-convencionais, convencionais ou pósconvencionais no que tange a aceitação ou negação da norma antirracista (KOHLBERG, 1976).

\section{IMPLICAÇÕES E DIREÇÕES FUTURAS: PENSANDO UMA AGENDA DE ENFRENTAMENTO DO RACISMO}

A partir das discussões sobre concepções e formas de ação do racismo, gostaríamos de destacar alguns pontos para combatê-lo, adotando a premissa de que suas manifestações individuais não podem ser desconectadas da sua produção cultural e institucional e vice-versa; ou seja, que estamos sempre lidando com um fenômeno sistêmico. O pressuposto aqui é aquele expresso no início do texto, se a análise é errada, então a estratégia política de combate pode não alcançar seus objetivos.

1) O foco principal da análise na psicologia social tem sido as formas de expressão e consequências psicológicas do racismo. Essa análise cria o risco de legitimar a asserção de que o racismo decorre de percepções negativas sobre os negros e de que, para eliminá-lo, basta eliminar essas percepções. Tal noção ignora a flexibilidade e persistência do racismo, ou seja, que ele atende também a interesses sociais e políticos em relações hierárquicas de dominação. A estratégia a esse respeito seria focalizar mais as práticas racistas no cotidiano no qual se manifestam, para procurar desvendar a quem elas interessam e o porquê (AHMED, 2004). Ou seja, desenvolver mais estudos sobre o dia-a-dia das relações racializadas, como elas se manifestam, em que circunstância, de quem, contra quem e que consequências práticas e emocionais trazem para os envolvidos.

2) O foco atual de boa parte da pesquisa psicossocial são as novas formas de racismo, destacando seu caráter automático e não controlável. O risco dessas análises é converter o racismo em algo natural e inescapável, a tal ponto que, em comum com as abordagens supremacistas, as teorias sobre os novos racismos acabem por conceber as categorizações raciais como naturais e inevitáveis. A alteridade definida nesses termos vira um problema racial (HOPKINS; REICHER; LEVINE, 1997). A estratégia que pode ser adotada para superar essa limitação é produzir mais estudos focalizando os modos sutis e complexos em que a diferença é produzida, racializada e apresentada como problemática. Também é importante começar a 
estudar os não racistas, para entender que elementos interferem na socialização desses indivíduos, desconstruindo a ideologia de socialização racista.

3) Há pouca sistematização de estudos e grupos de pesquisadores do tema do racismo no Brasil. Cria-se o risco de que as análises se tornem parciais, sem integração e sem acompanhamento amplo do fenômeno e das suas consequências, produzindo as condições para um progressivo aumento da violência racial no país. A estratégia aqui deve ser a promoção de redes integradas de pesquisa e de apoio a minorias, a exemplo do "Blacks lives matter" dos EUA. Pode-se também criar observatórios, a fim de monitorar, receber denúncias e desenvolver melhores e mais amplas análises do fenômeno e das suas consequências, a exemplo do Observatório de Discriminação Racial no Futebol.

\section{CONCLUSÕES}

Finalmente, vamos retomar nossa questão inicial e tentar responder o que há de novo no "novo" racismo do Brasil. O racismo nacional continua sendo o da exclusão do outro, com base em explicações/justificativas não racistas. No entanto, podemos falar de uma espécie de "retorno do reprimido", no contexto atual, graças à onda conservadora que, desde os movimentos de rua de 2013, tem se alastrado pelo país. Talvez estejamos diante de um "um efeito rebote". O preconceito teria retornado com força e virulência, alimentado pelo ressentimento das classes médias pelo avanço social dos negros e de outras minorias no Brasil, o qual substanciou a emergência das narrativas de conservadoras e reacionárias contra as minorias sociais. Outra explicação possível é a de uma suposta suspensão da ordem do "politicamente correto", também promovida nos últimos anos por intelectuais conservadores, o que pode ter estimulado muitos cidadãos a dizerem o que "não podia ser dito", fomentando manifestações mais abertas de ódio aos diferentes. Tudo isso potencializado pelas redes sociais e o quase anonimato e inimputabilidade que elas possibilitam. Enfim, essas e muitas outras explicações complementares são necessárias para entender as mudanças nas formas de expressão do racismo nacional. Mas, não se pode perder de vista que a mudança de aparência não alterou a essência do racismo no Brasil.

Nos Estados Unidos, o racismo também mudou sua aparência, sem alterar sua essência. Permanece a oposição ao acesso dos negros e latinos nas universidades; permanece a oposição ao direito de voto; raramente norte-americanos brancos têm um amigo íntimo negro; isto, para não dizer do "retorno" dos assassinatos motivados por racismo (ZURIFF, 2014).

Por tudo isso, o racismo, como representação social (VALA, 2015), tem o seu núcleo central pouco afetado pelos contextos mais contingentes. O que parece ocorrer é que o contexto permite alterar algumas normas e, com elas, as periferias do "politicamente correto", de forma 
que o racismo mude e se torne mais aberto. No núcleo central do fenômeno, contudo, permanecem intactas as crenças e interesses de dominação que têm garantido sua persistência e flexibilidade, fazendo com que se manifeste com mais força quando aquilo que ele protege é ameaçado.

Assim, o antídoto mais eficiente para combater esse vírus é aquele que muda suas condições institucionais ou estruturais de reprodução e incubação, algo que combata a perpetuação das desigualdades entre os grupos. Um bom exemplo de tal antídoto são as Políticas Públicas Ação Afirmativa para educação, inclusão e distribuição de renda. Elas podem, se executadas com acerto, gerar mudança nos níveis culturais e individuais de manifestação do racismo.

\section{REFERÊNCIAS}

ABOUD, Frances E. Children ; Prejudice. Oxford: Basil Blackwell, 1988.

ADORNO, T. W., FRENKEL-BRUNSWICK, E., LEVINSON, D.J. SANFORD, R.N. The authoritarian personality. New York: Harper, 1950.

AHMED, S. (2004). Declarations of whiteness: The non-performativity of anti-racism. Borderlands, 3, 2: 1-15.

ALLPORT, G. W. The nature of prejudice. $3^{\mathrm{a}}$ Ed. Wokingham: Addison-Wesley, 1954/1979.

AL-MOMANI, K., DADOS, N., MADDOX, M., WISE, A. Political Participation of Muslims in Australia. Working paper. Department of Social Security - Australian Government, 2010.

ARCOVERDE, L. (27/07/2018). Crimes de racismo e injúria racial crescem 29\% em São Paulo em 2018. Acessível em https://g1.globo.com/sp/sao-paulo/noticia/2018/07/27/crimesde-racismo-e-injuria-racial-crescem-29-em-sao-paulo-em-2018.ghtml

BEN BRIKA, J., LEMAINE, G.; JACKSON, J. Racism and Xenophobia in Europe. Bruxelas: European Commission, 1997.

BERRY, J. W., POORTINGA, Y. H., SEGALL, M. H., ; DASEN, P. R. Crosscrtlturalpsychology: Research and applicarions. New York: Cambridge University Press, 1992.

BOBO, L.; KLUEGEL, J.R. 'Status, Ideology, and Dimensions of Whites' Racial Beliefs and Attitudes: Progress and Stagnation'. In S.A. Tuch and J.K. Martin (eds), Racial Attitudes in the 1990s: Continuities and Change, Westport, CT: Praeger, 93-120, 1997.

BOBO, L. L. D. Racism in Trump's America: reflections on culture, sociology, and the 2016 US presidential election. The British Journal of Sociology, 68, 85-104, 2017.

BONILLA-SILVA, E. Racism without Racists: Color-blind Racism and the Persistence of Racial Inequality in the United States. Lanham, MD: Rowman and Littlefield, 2013.

BONILLA-SILVA, E. The Structure of Racism in Color-Blind, "Post-Racial" America. American Behavioral Scientist, 59(11) 1358-1376. DOI: 10.1177/0002764215586826, 2015.

BROWN, R. J. Prejudice: its social psychology. Oxford, uk: Blackwell, 1995.

CAMINO, L. Uma abordagem psicossociológica no estudo do comportamento político. Psicologia e Sociedade, 8 (1), 17-42, 1996. 
CAMINO, L., SILVA, P., ; MACHADO, A. As novas formas de expressão do preconceito racial no Brasil: estudos exploratórios. In M. E. O. LIMA E M. E. PEREIRA (Orgs.), Estereótipos, preconceitos e discriminação: perspectivas teóricas e metodológicas (pp. 121140). Salvador: EDUFBA, 2004.

CODJOE, H. M. Can blacks be racist? In: pens of many colours. Eva C. KARPINSKI (Ed.) Scarborough: Thomson-Nelson, 2002.

COHEN, C.J., FOWLER, M., MEDENICA, V.E., ; ROGOWSKI, J.C. The 'Woke' Generation? Millennial Attitudes on Race in the US. Acessível em https://genforwardsurvey.com/assets/uploads/2017/10/GenForward-Oct-2017-FinalReport.pdf, 2017.

CRANDALL, C.S., ESHLEMAN, A., ; O'BRIEN, L. Social norms and the expression and supression of prejudice: The struggle of internalisation. Journal of Personality and Social Psychology, 82, 359-378, 2002.

CRUZ, N.R. Cultura política, autoritarismo e desigualdade: as limitações à efetivação dos direitos humanos no Brasil. (Axe I, Symposium 2). Anais do VI Congreso CEISAL.Toulouse, France, 2010.

DESTAK (20/11/18). Denúncias de discriminação racial aumentam 43,75\% de 2017 para 2018. Acessível em https://www.destakjornal.com.br/cidades/rio-dejaneiro/detalhe/denuncias-de-discriminacao-racial-aumentam-4375-de-2017-para-2018 DOISE, W. (2002). Da Psicologia Social à Psicologia Societal. Psicologia: Teoria e Pesquisa, 18, 27-35.

DOVIDIO, J.F.; GAERTNER, S.L. On the nature of contemporary prejudice: the causes, consequences, and challenges of aversive racism. In J.L. Eberhardt ; S.T. Fiske (Eds.), Confronting Racism: The problem and the response (pp. 3-32). Califórnia: SAGE, 1998.

ESTADÃO (23/10/2017). O avanço do racismo. Acessível em http://infograficos.estadao.com.br/esportes/o-avanco-do-racismo/

FERNANDES, F. O Negro no mundo dos brancos. São Paulo: Difusão Europeia do Livro, 1966.

FISHBEIN, H. D. Peer prejudice and discriminação: The origins of prejudice (2 ed.). Mahwah: Lawrence Erlbaun Associates. Fishbein, 2002.

FOLHA DE SÃO PAULO (06/10/2017). Tendência para o autoritarismo é alta no Brasil, diz estudo. Acessível em https://www1.folha.uol.com.br/poder/2017/10/1924781-tendencia-parao-autoritarismo-e-alta-no-brasil-diz-estudo.shtml

FOLHA DE SÃO PAULO (13/03/2019). Veja quem são as vítimas do ataque em Suzano, na Grande São Paulo. Disponivel em https://www1.folha.uol.com.br/cotidiano/2019/03/vejaquem-sao-as-vitimas-do-ataque-em-suzano-na-grande-sao-paulo.shtml

FREDRICKSON, G. M. Racism: A short history. Princeton: University Press, 2002.

FREYRE, G. (Casa-grande e senzala: formação da família brasileira sob o regime de economia patriarcal. Lisboa: Edição Livros do Brasil, 1933/1983.

GAERTNER, S.L., ; DOVIDIO, J.F. The aversive form of racism. In J.F. Dovidio, ; S.L. Gaertner (Eds.), Prejudice, discrimination, and racism: Theory and research (pp. 61-89). Orlando, FL: Academic Press, 1986.

GUILLAUMIN, C. Sexe, race et pratique du pouvoir: l'idée de nature. Paris: Côte-Femmes Editions, 1992. 
HIRSCHFELD, L.A. Natural assumptions: race, essence, and taxonomies of human kinds. Social Research, 65, 331-349, 1998.

HOPKINS, N., REICHER, S., ; LEVINE, M. On the parallels between social cognition and the "new racism". British Journal of Social Psychology, 36, 305-339, 1997.

HOYT JR C. (The Pedagogy of the Meaning of Racism: Reconciling a Discordant Discourse. Social Work 57 (3), 225-234, 2012.

INGLEHART, R., ; NORRIS, P. Trump, Brexit and the Rise of Populism. Working Paper Series 26. Boston, MA: Harvard Kennedy School, 2016.

JACKMAN, M. R. The Velvet Glove: Paternalism and Conflict in Gender, Class, and Race Relations. Berkeley: University of California Press, 1994.

JACKMAN, M. R., ; Muha, M. J. Education and intergroup attitudes: Moral enlightenment, superficial democratic commitment, or ideological refinement? American Sociological Review, 49, 751-769, 1984.

JAVORČÍKOVÁ, J. "Smiling Discrimination” in Canadian Society". The Central European Journal of Canadian Studies, 5, 123-131, 2005.

KAKUTANI, M. A morte da verdade: notas sobre a mentira na era Trump. Rio de Janeiro: Editora Instrínseca, 2018.

KELMAN, H.C. Compliance, identification, and internalisation: three processes of attitude change. Journal of Conflict Resolution, 2, 51-60, 1958/1993.

KOHLBERG, L. Moral stages and moralization: The cognitive-developmental approach. In T. Lickona (Ed.), Moral development and behavior: Theory, research and social issues (pp. 31-53). Nova York: Holt Rinehart and Winston, 1976.

LIMA, B.D.T. de C. ; SANTOS, E.A.C. Socialização e dominação: a Escola de Frankfurt e a cultura. Tempo social [online], 30, 123-141, 2018.

LIMA, M.E.O. ; VALA, J. Sucesso social, branqueamento e racismo. Psicologia: Teoria e Pesquisa, 20(1), 11-19, 2004a.

LIMA, M.E.O. ; VALA, J. As novas formas de expressão do preconceito e do racismo ISSN 1413-294X. Estudos de Psicologia (Natal), Natal, v. 9, n.3, p. 401-412, 2004 b.

LIMA, M.E.O. ; ALMEIDA, A. M. As representações sociais construídas sobre os índios em Sergipe: Ausência e invisibilização. Paidéia, 20, 17-27, 2010.

LIMA, M.E.O. Normas sociais e racismo: Efeitos do individualismo meritocrático e do igualitarismo na infra-humanização dos negros. Tese de Doutoramento, Instituto Superior de Ciências do Trabalho e da Empresa, Lisboa, 2002.

LIMA, M.E.O. Da diferença à indiferença: Racismo contra Índios, Negros e Ciganos no Brasil. In: TECHIO, E.M. E LIMA, M.E.O. (Org.), Cultura e Produção de Diferenças: estereótipos e preconceito no Brasil, Espanha e Portugal. (pp. 217-245), $1^{\mathrm{a}}$ ed.

Techonopolitik: Brasília, 2011.

LIMA, M.E.O., ARAUJO, E.M. DOS S., BARBOSA, I.H. ; ALMEIDA, J. do N. (under revision). Racismo como vitmismo: Desenvolvimento de uma escala de racismo.

LIMA, M.E.O., FARO, A., ; DOS SANTOS, M. A desumanização presente nos estereótipos de índios e ciganos. Psicologia: Teoria e Pesquisa, 32, 219-228, 2016. 
LIMA, M.E.O., NEVES, P.S. DA C., ; SILVA, P. B. A implantação das cotas na Universidade: paternalismo e ameaça à posição dos grupos. Revista Brasileira de Educação, 19, 141-164, 2014.

LIMA, M.E.O., PINHEIRO, C., PACHECO, J., ; LIMA, C. Normas sociais e preconceito: O impacto da igualdade e da competição no preconceito automático contra os negros. Psicologia. Reflexão e Crítica, 19, 309-319, 2006.

LINS, S.L.B., LIMA, T.J.S. DE, SOUZA, L.E.C. DE, NUNES, A.L., ; CAMINO, L. Racial prejudice and social values. Psico-USF, 22, 309-321, 2017.

MICHAEL, G. The Rise of the Alt-Right and the Politics of Polarization in America. Skeptic, 22, 9-17, 2017.

MILES, Robert. Racism. Londres: Routledge, 1989.

MUIS, J. ; IMMERZEEL, T. Causes and consequences of the rise of populist radical right parties and movements in Europe. Current Sociology Review, 65, 909-930, 2017.

PEREIRA, C. ; VALA, J. Do preconceito à discriminação justificada. In-Mind_Português, 1, 2-3, 1-13, 2010.

PETTIGREW, T.F. Personality and social-cultural factors in intergroup attitudes: a crossnational comparison. Journal of Conflict Resolution, 2, 29-42, 1958.

PIERUCCI, A.F. Ciladas da diferença. Tempo social, 2(2), 7-33, 1990.

ROKEACH, M. The open and closed mind. New York: Basic Books, 1960.

SIDANIUS, J., PRATTO, F., ; BOBO, L. Social dominance orientation and the political psychology of gender a case of invariance? Journal of Personality and Social Psychology, 67, 998-1011, 1996.

TAGUIEFF, P-A. (O anti-racismo em crise: elementos de uma crítica reformista. Em M. Wieviorka (Ed.). Racismo e modernidade (pp.308-344). Lisboa: Bertrand.

TAJFEL, H. (1981). Human groups and social categories: Studies in social psychology. Cambridge: Cambridge University Press, 1995.

TURRA, C., ; VENTURI, G. Racismo Cordial: a mais completa análise sobre preconceito de cor no Brasil. São Paulo: Ática, 1995.

TYLER, T.R. Psychological perspectives on legitimacy and legitimation. Annual Review of Psychology, 57, 375-400. Doi: 10.1146/annurev.psych.57.102904.190038, 2006.

VALA, J. ; LIMA, M.E.O. Individualismo meritocrático, diferenciação cultural e racismo. Análise Social, XXXVII, 181-207, 2002.

VALA, J. ; PEREIRA, C. Racism: An Evolving Virus. Proceedings of the British Academy 179, 49-70., 2012.

VALA, J. Racismos: representações sociais, preconceito racial e pressões normativas. In J. C. Jesuíno, F. R. P. Mendes ; M. J. Lopes (Eds.), As representações sociais nas sociedades em mudança, pp. 153-183. (Coleção Psicologia Social). Petrópolis, RJ: Vozes, 2015.

VALA, J., LOPES, D., ; BRITO, R. A construção social da diferença: racialização e etnicização das minorias. In: J. Vala (Coord.), Novos Racismos: Perspectivas comparativas (pp. 145-179). Oeiras: Celta, 1999.

van den BERGHE, P. Race and ethnicity: a sociobiological perspective. Ethnic and Racial Studies, Vol. 1, no 4, Outubro, 1978/2001. 
VIRDEE, S. ; MCGEEVER, B. Racism, Crisis, Brexit. Ethnic and Racial Studies, 41, 18021819. DOI: 10.1080/01419870.2017.1361544, 2018.

WETHERELL, M. ; POTTER, J. Mapping the language of racism: discourse and the legitimation of expoliation. Hertfordshire: Harvester Wheatsheaf, 1992.

WETHRELL, M. (Group conflict and the social psychology of racism. In: M. Wetherell (Ed.), Identities, Groups, and Social Issues. (pp. 175-238). SAGE: London, 1996.

WIEVIORKA, M. The arena of racism. London: Thousand Oaks, Calif. Sage Publications, 1995.

ZURIFF, G. E. Racism Inflation. American Psychologist, 69, 309-310, 2014. 